Available online on 15.09.2020 at http://ujpr.org
Universal Journal of Pharmaceutical Research
An International Peer Reviewed Journal
Open access to Pharmaceutical research

\title{
ASSESSMENT OF THE RISK OF TYPE 2 DIABETES AMONG HEALTHY WITHOUT DIABETES IN SUDAN USING THE FINDRISC TOOL Osman Abdalrhman Osman ${ }^{1}{ }^{10}$, Ali Awadallah Saeed ${ }^{2}{ }^{\circledR}$, Mohamed Awad Mousnad ${ }^{3 *}$, Azza Hamid ${ }^{1}$ \\ ${ }^{I}$ Faculty of Clinical and Industrial Pharmacy, National University, Sudan. ${ }^{2}$ Department of Pharmacology and Therapeutics, Pharmacy Program, Napata College, Sudan. ${ }^{3}$ Department of Pharmacy Practice, Faculty of Pharmacy, International University of Africa, Sudan.
}

\section{ABSTRACT}

Background and objective: Diabetes is increasingly recognized as a serious public health concern worldwide. The risk assessment of type 2 diabetes can be done through a risk questionnaire that provides an accurate, low-cost, educational and timeeffective method for this. By early identification of people at risk of developing diabetes and if it is confirmed that they are in the pre-diabetes stage, adequate care is provided to them through lifestyle interventions or even hypoglycemic drugs if needed, thus delaying or preventing their progression to diabetes. Therefore, this study aimed to assess the risk of developing type 2 diabetes (T2DM) among healthy Sudanese without diabetes in Khartoum.

Methods: A cross-sectional study from Nov 2016-March 2017 comprising 122 adult participants, age ( $>20$ yrs) visiting the garden yard located at airport street at Khartoum district without a diagnosis of T2DM was carried out. The risk of developing T2DM was assessed using the validated and widely used Finish diabetes risk score (FINDRISC) Total Risk Score of each participant was analysed and compared. Knowledge assessment tool and Anthropometric measurements were also used.

Results: 122 participated in the study, the mean age of the participants was $31.55 \pm 10.122$, the mean BMI was $25.718 \pm 5.813$ and the mean of waist circumstances $90.2 \pm 16.63$. Estimated risk of developing T2DM in 10 years of study for participants according to FINDRISC, only $3.3 \%$ have a high risk. The risk factors for the participants in the study for developing DM type 2 were $66.4 \%$ has positive family history, $44.3 \%$ were overweight or obese, has $41.8 \%$ limited physical activity and $27.9 \%$ has central obesity. The pattern of vegetables and fruits daily intake according to FINDRISC only $36.1 \%$ from participants. Significant positive correlation $(\mathrm{r}=0.395, p=0.000)$ High risk score of FINDRISC is $>14$, Estimated age: $\mathrm{Y}=24.1+(0.9 \mathrm{x} 15)=37.9 \approx 38$ years. Significant positive correlation $(\mathrm{r}=0.6, p=0.000)$ High risk score of FINDRISC is $>14$, Estimated BMI: $\mathrm{Y}=19.24+(0.8 \times 15)=31 \mathrm{Kg} / \mathrm{m}^{2}$.

Conclusion: The knowledge about diabetes risk factors, classical symptoms and common complication was not satisfactory. None of the "at high" risk had their risk further investigated. While $25 \%$ adapted health their lifestyle. Large scale studies to test the validity of FINDRISC in Sudanese population should be conducted. Development of Sudanese population specific risk score that take into count the local risk factors is warranted.

Keywords: Assessment, Finish diabetes risk score (FINDRISC), Sudanese, Type 2 DM.

Article Info: Received 28 May 2020; Revised 26 July; Accepted 19 August, Available online 15 September 2020

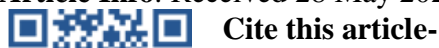

Osman OA, Saeed AA, Mousnad MA, Hamid A. Assessment of the risk of type 2 diabetes among healthy without diabetes in Sudan using the findrisc tool. Universal Journal of Pharmaceutical Research 2020; 5(4):3741. DOI: https://orcid.org/0000-0003-2680-2450

Address for Correspondence:

Dr. Mohamed Awad Mousnad, International University of Africa (IUA), Khartoum, Sudan, Tel: +249-912325864, E-mail: m_abdalaziz@yahoo.com

\section{INTRODUCTION}

Diabetes is increasingly recognized as a serious, worldwide public health concern ${ }^{1}$. In 2010 it was estimated that 285 million people are living with diabetes $^{2}$, the number increased to 366 million in $2011^{3}$, then escalated to 415 million in $2015^{4}$. Low-and middle-income countries have the highest proportion of people with diabetes ${ }^{3}$. International diabetes federation (IDF) estimates that by 2040 there will be 642 million people living with diabetes worldwide ${ }^{4}$. In Sudan, there were 3 million cases of diabetes in $2014^{5}$. One of the most worrying characteristics of this rapid growth is that T2 DM is becoming more prevalent among children, adolescents, and young adults ${ }^{6}$; indeed Osman et al., reported that prevalence of T2DM is now increasing among Sudanese children and adolescents ${ }^{7}$. This may be due to increasing prevalence of obesity, sedentary lifestyle and physical inactivity ${ }^{8}$. A primary concern about T2DM is that it remains clinical unapparent for long time ${ }^{9}$. The onset of T2DM may 
occur as early as 9-12 years before its clinical diagnosis ${ }^{10}$. Globally, $45.8 \%$ or 174.8 million people are estimated to be living with undiagnosed T2DM; about $83.8 \%$ of them live in low-and middle income countries $^{11}$. Nevertheless even those undiagnosed people are placed at increased risk for developing diabetes complications. At time of diagnosis, complications are established in $20-30 \%$ of the patients $^{12}$. There is an intermediated stage between normoglycemia and diabetes which is pre-diabetes ${ }^{13}$. Approximately 5-10\% of pre-diabetics per year will progress to diabetes ${ }^{14}$. T2DM can be delayed or even prevented in high risk subjects ${ }^{15,16}$ which lead to delaying incidence of complications and comorbidities ${ }^{19}$. Life style interventions targeting weight loss and increasing physical activity and improving diet has produced a 30-60\% reduction in the risk of developing T2DM ${ }^{17}$. Pharmacotherapy has been also used; metformin, acarbose and troglitazone with 31, 36 , and $56 \%$ risk reduction respectively ${ }^{18}$.

Various risk scores are available, the Finnish diabetes risk score has been used in this study as it received the IDF Recommendation as a simple, fast, non-invasive, inexpensive, and reliable tool to identify individuals at high risk for $\mathrm{T}_{2} \mathrm{DM}^{19}$, and it is validated in many countries with good performance ${ }^{20}$. This was concluded by Rowan P.C. and his colleagues after performing risk assessment followed by point of care glycosylated haemoglobin (HbA1C) test which showed positive correlation with the risk score as the risk increased the HbA1C value also increased ${ }^{25}$. Diabetes care represents a real challenge in Sudan for both healthcare system and patients ${ }^{21-23}$. According to the annual health report issued by the ministry of health for 2015, among the ten leading disease treated as outpatients diabetes was the fifth, and form the ten leading causes of hospital admissions it was the seventh ${ }^{24}$. Identification of individuals at high risk for developing diabetes has been a major concern worldwide, in Community-based settings, a study conducted in Libya by Abduelkarem et al., ${ }^{26}$, second study in Nigeria by Alebiosu et al., ${ }^{27}$ and third one in Saudi Arabia by Alzohairy M. and Hassan M. ${ }^{28}$, all of these studies used the FINDRISC as a tool for risk assessment. Likewise two studies has been conducted in India using the Indian diabetes risk score by Subramani et al. ${ }^{29}$ in rural area of Sripuram and by Anjana et al. ${ }^{30}$ in urban slum of Hubli. Furthermore in rural West Virginia a study has been conducted by Misra et al., ${ }^{31-33}$. There is a significant difference in the percent of individuals at high risk in rural areas compared to those in urban areas which is not surprising since urbanization leads to adapting more westernized lifestyle therefore increasing the risk of developing $\mathrm{T}_{2} \mathrm{DM}^{34}$. This study aims at assessing the risk of developing type 2 diabetes mellitus (T2DM) among healthy non-diabetic Sudanese in Khartoum city during the peroid from November 2016 to February 2017. The study was community based study divided into two phases:

Phase one: cross-sectional observational study, where all participants had their risk of developing diabetes assessed and provided with verbal counseling.
Phase two: educational interventional for those found at high/very high risk, their knowledge regarding diabetes was assessed, then they were provided with verbal education by feedback method with emphasis on importance of early testing for diabetes and contact information obtained, average interview time was 1525 minutes. They were contacted after two weeks to check whether they went to investigate their risk status by doctor or not.

\section{MATERIALS AND METHODS}

The study conducted during the period from November 2016 to March 2017 for 122 Non-diabetic Sudanese adults visiting public gathering places mainly the Green yard Khartoum city, Sudan selected by convenient sampling technique. It has been selected as place for data collection as it represents a major destination for entertainment for families and individuals with average number of visitors approximately 10-15 thousand at weekends from all age groups and diverse areas of Khartoum city. To determine the percent of individuals at high risk of T2DM using the Finnish diabetes risk score. To determine the frequencies of most common risk factors predisposing individuals to develop T2DM. To assess the effect of perceived risk on those at high risk behavior to seek further medical care and intention to adopt healthy lifestyle.

The data were collected by three tools:

Finish diabetes risk score (FINDRISC):

Risk score form is a one-page questionnaire containing eight questions, with categorized answers, about age, body mass index (BMI, waist circumference, physical activity, daily consumption of fruits, berries or vegetables, history of antihypertensive drug treatment, history of high blood glucose, and family history of diabetes. The form was translated to Arabic language and layout has been adjusted.

\section{Knowledge assessment tool:}

Structured questionnaire to assess the high/ very high risk group perceptions regarding diabetes causes, signs and symptoms, risk factors, complications of diabetes, early screening attitude toward risk status also demographic information obtained as well as contact information.

\section{Anthropometric measurements}

Including body weight, height, waist circumference and Body Mass Index (BMI).

\section{Ethical consideration:}

Ethical approval was obtained from faculty of pharmacy, national university. Participation was completely voluntary and verbal consent was obtained from all participants after providing full explanation. SPSS version 21 (IBM SPSSInc., Chicago, IL) was used for data entry and analysis. The variables (age, weight, BMI and WC) were expressed as mean \pm standard deviation. The frequencies of risk factors were expressed as number (\%). Statistical association between nominal variables was estimated using the chisquare test. Linear regression was employed to estimate the correlation between age, BMI and risk score. 
Table 1: Characteristics of study participants.

\begin{tabular}{cccc}
\hline Study variable & Total $(\mathbf{n}=122)$ & Males $(\mathbf{n}=\mathbf{7 5})$ & Females $(\mathbf{n}=\mathbf{4 7})$ \\
\hline Age & $31.55 \pm 10.122$ & $32.95 \pm 10.865$ & $29.3 \pm 8.436$ \\
BMI & $25.718 \pm 5.813$ & $25.647 \pm 5.944$ & $25.831 \pm 5.66$ \\
Waist circumstances & $90.2 \pm 16.63$ & $91.94 \pm 16.379$ & $87.415 \pm 16.823$ \\
\hline
\end{tabular}

All (mean \pm standard deviation), Age in years, BMI in $\mathrm{kg} / \mathrm{m}^{2}$, Waist circumference in centimeters

\section{RESULTS}

122 participated in the study, $61.5 \%$ from them male while $38.5 \%$ were female, the mean age of the participants was $31.55 \pm 10$, the mean BMI was $25.718 \pm 5.813$ and the mean of waist circumstances $90.2 \pm 16.63$ as stated in Table 1 . The estimated risk of developing T2DM in 10 years of the study for the participants according to FINDRISC, only $3.3 \%$ has high risk, $19.9 \%$ moderate elevated risk, $34.9 \%$ slightly elevated risk and $41.9 \%$ has low risk for developing DM type 2 in the next 10 years as shown in Table 2.

Table 2: Estimated risk of developing T2DM in 10 years of the study participants according to FINDRISC.

\begin{tabular}{cc}
\hline $\begin{array}{c}\text { Estimated risk of } \\
\text { developing T2 DM in }\end{array}$ & Percent \\
10 years & \\
\hline Low & 41.9 \\
Slightly elevated & 34.9 \\
Moderate & 19.9 \\
High & 3.3 \\
\hline
\end{tabular}

$66.4 \%$ has positive family history, $44.3 \%$ were overweight or obese, has $41.8 \%$ limited physical activity and $27.9 \%$ has central obesity as shown in Table 3. Only $36.1 \%$ from participant's daily take vegetables and fruits while $63.9 \%$ didn't take it daily as shown in Figure 1. The estimated age at which participants are at high risk according to FINDRISC: $\mathrm{Y}=24.1+(0.9 \times 15)=37.9 \approx 38$ years. Significant positive correlation $(\mathrm{r}=0.395, p=0.000)$, High risk score of FINDRISC is $>14$.

Table 3: Frequencies of risk factors among study participants.

\begin{tabular}{lc}
\hline $\begin{array}{l}\text { Frequencies of risk } \\
\text { factors among } \\
\text { participants }\end{array}$ & Percent \\
\hline Elder age & 13.9 \\
Over weight/ Obese & 44.3 \\
Central obesity & 27.9 \\
Limited physical activity & 41.8 \\
Anti hypertensive & 4.9 \\
medication use & 15.6 \\
History of abnormal & \\
blood glucose level & 66.4 \\
\hline Positive family history & 6 \\
\hline
\end{tabular}

The estimated body mass index at which participants are at high risk: $\mathrm{Y}=19.24+(0.8 \times 15)=31 \mathrm{Kg} / \mathrm{m}^{2}$, Significant positive correlation $(\mathrm{r}=0.6, p=0.000) \mathrm{High}$ risk score of FINDRISC is $>14$.

\section{DISCUSSION}

Participants were predominantly aged less than 45 years. Males constituted a large portion because females showed a conservative behavior toward revealing their age and weight. Individuals found at high risk of developing DM type 2 constituted only small portion $(3.3 \%)$ of thesmall sample size. Similarly Alebiosu et al., ${ }^{27}$, Alzohairy ${ }^{28}$, Subramani et al. ${ }^{29}$ and Abduelkarem et al. ${ }^{26}$ reported a 5.05\%, $9.8 \%, 12.1 \%$ and $12.3 \%$ individual at high risk respectively. In contrast to studies of Anjana et al. ${ }^{30}$ and Misra et al.,${ }^{31}$ whereas $45 \%$ and $61.8 \%$ were at high risk respectively.

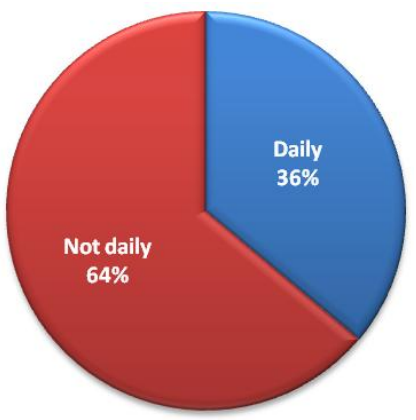

Figure 1: Patterns of vegetables and fruits intake among study participants.

Moderately risk was detected in $19.7 \%$ similar to Abduelkarem et al., $20 \%{ }^{26}$, and $77 \%$ were at low/ slightly elevated risk similar proportion to findings of Alzohairy and Hassan $70.6 \%{ }^{28}$. Majority of participants were aged less than forty five years old therefore they had less age associated risk. Additionally majority of them had neither family history nor personal history of abnormal blood glucose level, two components that are given high score in FINDRISC (5 points for each). First risk factor is the family history of diabetes either its type 1 or 2 . Positive family history it significantly associated with risk score, reported by $66.4 \%$ of the study participants and 4/ 4 of those found at high risk reported positive family history. Similar findings reported by Misra et al., ${ }^{31} 65 \%$ had family history of diabetes. About $44.3 \%$ had BMI $\geq 25 \mathrm{~kg} / \mathrm{m}^{2}(24.6 \%$ were overweight and $19.7 \%$ were obese) contradictory to the study by Alzohairy and Hassan in Saudi Arabia ${ }^{28}$ where $96.5 \%$ reported to have BMI $\geq 25 \mathrm{~kg} / \mathrm{m}^{2}$. Although the sample size are not comparable as early mentioned even though we compare in term of portion of sample. There was significant association between BMI and risk score $(p=0.000)$. Limited physical activity ( $<30$ minutes of exercise) was reported by $41.8 \%$ of participants. Again Abduelkarem et al., reported that $57.3 \%$ of their participants had limited physical activity ${ }^{26}$. According to FINDRISC the physical activity is measure in term of performing 30 minutes of exercise at work or during leisure time, it would have been more appropriate to specify the type of exercise such as brisk walking, intensity of exercise being aerobic or anaerobic. Central obesity detected in $27.9 \%$ of the study participants which increases the risk of developing T2 DM. Significant association with risk 
score was found $(p=0.000)$. History of abnormal blood glucose level was reported by $15.6 \%$, during a health examination or illness or gestational diabetes in females and significantly associated with the risk score $(p=0.000)$. A total of $13.9 \%$ aged $\geq 45$ years, the process of aging results in declining metabolic capacity of body and ability to secret or utilize the insulin to regulate blood sugar. Increasing age not only increases the risk developing T2DM but also other cardiovascular diseases. Irregular daily consumption of vegetables and fruit (component of FINDRISK component) was reported by majority of the participants, Similar to study by Naranjo et al., ${ }^{33}$. In area of risk results and association with developing type $2 \mathrm{DM}$ in each gender, there was no significant difference between males and females regarding risk score $(p=0.076)$. Males risk results are associated with their BMI, WC ( $p=0.000$ for both), history abnormal blood glucose level $(p=0.005)$ and physical activity $(p=0.004)$, while age and family history didn't show any association ( $p=0.157$ and 0.196 respectively). Females risk of developing T2 DM was associated with their BMI and WC ( $p=0.00$ for both), similar to findings reported by Alebiosu et al. ${ }^{26}$ and Misra et $a l .,{ }^{31}$. In area of knowledge of high risk group about $\mathrm{T}$ 2 DM, family history and unhealthy diet were the most acknowledged risk factors of T2 DM. Regarding classical symptoms polyuria was the most acknowledged symptoms of diabetes, polydipsia and polyphagia were moderately known. Concerning common complications, nephropathy was well known; retinopathy and neuropathy were moderately known. One of the individuals had completely missing knowledge regarding all items assessed.

\section{Study limitations}

The small sample size that hindered the results incomparable with previous studies resulted from two factors: the first is time and resources constrain and the validity of Finnish diabetes risk score among Sudanese is not tested thus it may over or underestimate the actual risk status.

\section{CONCLUSION}

Out of the 122 individuals had their risk assessed, 3.3\% were found at high risk, $19.7 \%$ were at Moderate and $77 \%$ were at low/ slightly elevated risk. The most common risk factors encountered were positive family history of diabetes $66.4 \%$, overweight/ obese status $44.3 \%$, limited physical activity $41.8 \%$ and central obesity $27.9 \%$. The knowledge about diabetes risk factors, classical symptoms and common complication was not satisfactory. None of the "at high" risk had their risk further investigated. While $25 \%$ adapted health their lifestyle.

\section{RECOMMENDATIONS}

Large scale studies to test the validity of FINDRISC in Sudanese population should be conducted, development of Sudanese population specific risk score that take into count the local risk factors is waranted and diabetes awareness programs should be commenced to raise awareness about seriousness of $\mathrm{T} 2$
DM and most important of all is preventability of T2 DM.

\section{AUTHOR'S CONTRIBUTION}

Osman Abdalrhman Osman has collected data and involved in writing of the article. Ali Awadallah Saeed has suggested for the hypothesis of the work. Mohamed Awad Mousnad: has written the article. Azza Hamid involves in the Hypothesis of the work and analyzing results.

\section{ACKNOWLEDGEMENTS}

The authors extend their thanks and appreciation to the International University of Africa (IUA), Khartoum, Sudan to provide necessary facilities for this work.

\section{CONFLICT OF INTEREST}

No conflict of interest associated with this work.

\section{REFERENCES}

1. Wild S, Roglic G, Green A, Sciree R, King H. Global prevalence of diabetes estimates for the year 2000 and projections for 2030. Diabetes Care 2004; 27(5):10471053. https://doi.org/10.2337/diacare.27.5.1047

2. Shaw JE, Sicree RA, Zimmet PZ. Global estimates of the prevalence of diabetes for 2010 and 2030. Diabetes Res Clin Pract 2010; 87 (1): 4- 14.

https://doi.org/10.1016/j.diabres.2009.10.007

3. Whiting DR, Guariguata L Weil C and Shaw J. IDF Diabetes Atlas: Global estimates of the prevalence of diabetes for 2011 and 2030. Diabetes Res Clin Pract 2011; 94:311-321.

4. Cho NH, Whiting D, Forouhi N, Guariguata L, et al, IDF diabetes atlas, $7^{\text {th }}$ edition, 2015, chapter 2: Methodology, Chapter 4: Diabetes by region 2015 36-67, https://doi.org/10.1016/j.diabres.2011.10.029

5. Zhang $P$, Zhang X, Brown J, Vistisen D, Sicree R, Shaw Jand Nichols G. Global healthcare expenditure on diabetes for 2010 and 2030. Diabetes Res Clin Pract 2010;87:293-301. https://doi.org/10.1016/j.diabres.2010.01.026

6. Zimmet PZ, Magliano DJ, Herman HW and Shaw J E., Diabetes: a $21^{\text {st }}$ century challenge, Lancet Diabetes and Endocrinology, 2014; Jan 2 (1): 56- 64. https://doi.org/10.1016/S2213-8587(13)70112-8

7. Osman HA, Elsadek H, Abdullah M. Type 2 diabetes in Sudanese children and adolescents. Sudanese J Ped 2013; 13(2):17-23. PMID: 27493369

8. Musaiger OA, Nabag FO, Al-Mannai M. Obesity, dietary habits, and sedentary behaviors among adolescents in Sudan: alarming risk factors for chronic diseases in a poor country. Food Nut Bull 2016;37(1):65-72, https://doi.org/10.1177/0379572116629244

9. Haris MI, Klein R, Welborn TA, Knuiman MW. Onset of NIDD occurs at least 4-7 years before clinical diagnosis. Diabetes Care 1992;15(7):815-825. https://doi.org/10.2337/diacare.15.7.815

10. Jessica Beagley, Leonor Guariguata, Clara Weil, Ayesha A. Motala, Global estimates of undiagnosed diabetes in adults. Diabetes Res Clin Pract 2014; 103: 150-160. https://doi.org/10.1016/j.diabres.2013.11.001

11. Michael J, Twigg, et al. Community pharmacy type 2 diabetes risk assessment: demographics and risk results. Int J Pharmacy Pract 2015; 23:80-82, https://doi.org/10.1111/ijpp.12139

12. Rajala U, Laakso M, Qiao Q, Keinanen-Kiukaanniemi S. Prevalence of retinopathy in people with diabetes, impaired glucose tolerance and normal glucose tolerance. Diab Care 1998; 21:1664-1669.

https://doi.org/10.2337/diacare.21.10.1664 
13. American diabetes association, diagnosis and classification of diabetes mellitus, Diabetes Care 2010; 33(1): S62- S69. https://doi.org/10.2337/dc14-S081

14. Adam GT, Herder C, Wolfgang R, et al. Pre-diabetes: a high-risk state for developing diabetes. Lancet J 2012; 379: 2279-2290. https://doi.org/10.1016/S0140-6736(12)60283-9

15. Gillies CL, Abrams KR, Lambert PC, et al. Pharmacological and lifestyle interventions to prevent or delay type 2 diabetes in people with impaired glucose tolerance: systematic review and meta-analysis. BMJ 2007; 334(7588): 299 https://doi.org/10.1136/bmj.39063.689375.55

16. Lindstrom Janna and et al, Sustained reduction in the incidence of type 2 diabetes by lifestyle intervention: follow-up of the Finnish Diabetes Prevention Study, Lancet, 2006 Nov 11; 368 (9548):1673-9, https://doi.org/10.1016/S0140-6736(06)69701-8

17. Charlotte L, Edwardson LJ, Gray TY, et al. Detection and early lifestyle intervention in those at risk of type 2 diabetes. European Med J Diab 2014; 2:48-57.

18. Sherwin RS, Anderson RM, et al. The prevention or delay of type 2 diabetes. Diabetes Care 2004; 27 Suppl 1:S47-54. https://doi.org/10.2337/dc11-S011

19. Lee CMY, Colagiuri S. Risk scores for diabetes prediction: the international diabetes federation predict-2 project. Diabetes Res Clin Practice 2013; 285-286. https://doi.org/10.1016/j.diabres.2013.01.024

20. Kengne AP, Joline WJB, Linda M Peelen, Karel GMM, et al. Non- invasive risk scores for prediction of type 2 diabetes (EPIC- Inter Act): a validation of existing models. Lancet Diab Endocrinol 2014; 2:19-29.29. https://doi.org/10.1016/S2213-8587(13)70103-7

21. Ahmed AM, Ahmed NH. Diabetes mellitus in Sudan: the size of the problem and possibilities of efficient care. Practical Diab Int 2001; 18(9) 324-327. https://doi.org/10.1002/pdi.292

22. Elrayah- Eliadarous H, Yassin K, Eltom M, et al. Direct costs for care and glycemic control in patients with type 2 diabetes in Sudan. Exp Clin Endocrinol Diab 2010; 118: 220 -225. https://doi.org/10.1055/s-0029-1246216

23. Mirghani HO. Demographic and clinical characteristics of diabetic patients attending an outpatient clinic in Omdurman, Sudan. Sudanese J Public Health 2013;8(2). https://doi.org/10.11604/pamj.2019.34.34.15161

24. National Health Information Centre, Sudan Federal Ministry of health, Annual health statistical report 2015; $101-109$
25. Rowan CP, Miadovnik LA, Riddell MC, et al. Identifying persons at risk for developing type 2 diabetes in a concentrated population of high risk ethnicities in Canada using a risk assessment questionnaire and pointof-care capillary blood HbA1c measurement. BMC Public Health 2014; 14: 929. https://doi.org/10.1186/1471-2458-14-929

26. Abduelkarem AR, et al. Risk calculation of developing type 2 diabetes in Libyan adults. Pract Diab Int 2009; 26(4):148-151. https://doi.org/10.1002/pdi.1359

27. Alebiosu OC, Familoni OB, Ogunsemi OO, et al. Community based diabetes risk assessment in Ogun state, Nigeria (World Diabetes Foundation project 08321). Indian J Endocrinol Metabolism 2013; 17:653-658. https://doi.org/10.4103/2230-8210.113756

28. Alzohairy M, Hasan M. Risk Estimation of type 2 diabetes and dietary habits among adult Saudi Nondiabetics in Central Saudi Arabia. Global J Health Sci 2011; 3(2), 123-133.

https://doi.org/10.5539/gjhs.v3n2p123

29. Subramani R, Devi U, Shankar U, et al. Assessment of risk of type 2 diabetes mellitus among rural population in Tamilnadu by using Indian diabetic risk score. Middle East J Sci Res 2014; 21(1):223-225. https://doi.org/10.5829/idosi.mejsr.2014.21.01.21151

30. Anjana P, Dattatreya DB. A Community based crosssectional study to identify individuals at high risk for diabetes in urban slums of Hubli. Int $\mathrm{J}$ Comm Med Public Health 2016; 3(1): 212-217, https://doi.org/10.18203/2394-6040.ijcmph20151565

31. Misra R, et al. Community based diabetes screening and risk assessment in rural West Virginia. J Diab Res 2016; 1-9. https://doi.org/10.1155/2016/2456518

32. Nisar N, Khan IA, Qadri MH, Sher SA. Knowledge and Risk assessment of diabetes mellitus at primary care level: A Preventive approach required combating the disease in a developing country. Pakistan J Med Sci 2008; 24 (5):667-72.

33. Adrian A, Naranjo, et al. Diabetes risk in a Cuban primary care setting in persons with no known glucose abnormalities. MEDICC Rev 2013; 15(2)16-19. PMID: 23686250

34. Venugopal V, Selvaraj K, Majumdar A, et al. Opportunistic screening for diabetes mellitus among adults at tending primary health center in Puducher y. Int J Med Sci Pub Health 2015;4 (9) 1206-1211. https://doi.org/10.5455/ijmsph.2015.03032015238 